Archivum, LXV, 2015, pp. 75-90

\title{
El origen de bable y su reinterpretación onomatopéyica
}

Recibido: 22/04/2015

Aceptado: 27/07/2015

\section{RESUMEN:}

En la explicación del origen de bable han prevalecido las hipótesis onomatopéyicas, tanto si se ha partido de la voz natural BABL como de los adverbios latinos BALBE y BARBARE; en particular del último, que proporciona una solución similar a ROMANICE (> romance) o VASCONICE (> vascuence). Cualquiera de las tres soluciones allana las dificultades fonéticas, pero no así las de contenido. Aquí sostenemos, como ya apuntó Munthe, que el étimo de bable es FabLa ("habla"). Si, por una parte, este evolucionó fonéticamente a fala en asturiano, como en gallego-portugués, por otra, su consonante inicial pasó a b- por reduplicación silábica. B-able surge, pues, de un cambio morfológico característico de la lengua familiar y análogo al del hipocorístico inglés B-ob a partir de R-ob(ert). La nueva configuración de la palabra ha facilitado su reinterpretación onomatopéyica.

PALABRAS CLAVE: reduplicación silábica, onomatopeya, latín vulgar.

\begin{abstract}
:
In the explanations given of the origin of the word bable onomatopoeic hypotheses have prevailed, based both on the natural term BABL and on the Latin adverbs BALBE and BARBARE. The latter is cited often in particular, suggesting a solution similar to ROMANICE (> romance) and VASCONICE (> vascuence). All three of these solutions resolve any phonetic difficulties, but do not deal with those related to content. In this article, we suggest that the etymon of bable is FABLA ("speech"), as has already been proposed by Munthe. If, on the one hand, this evolved phonetically to fala in Asturian, as in Galician-Portuguese, on the other, its initial consonant became b- as a result of
\end{abstract}


syllabic reduplication. B-able arises, therefore, as the result of a morphological change characteristic of familiar language and similar to the hypocoristic English B-ob from $\mathrm{R}$-ob(ert). The word's new configuration then gave rise to its onomatopoeic reinterpretation.

KEY WORDS: syllabic reduplication, onomatopoeia, Vulgar Latin.

1. El origen de bable. Dificultades históricas, fonéticas y significativas de la palabra

La primera vez que nos fijamos en la palabra bable y tratamos de percibir su sentido etimológico, sentimos que bajo su forma un tanto pintoresca latía el viejo sustantivo latino fabula, con el significado que convenía a su designación de habla regional. El DRAE que, por su actualidad y autoridad académica, suele ser nuestra primera consulta lexicográfica la presentaba como voz onomatopéyica y así se mantiene en la última edición. Sin embargo, hace tiempo que, sin mayor indagación, la habíamos incluido en la lista de onomatopeyas sospechosas. La invitación cursada por el Prof. Alfonso García Leal para pronunciar una ponencia en el XI Congreso Internacional de Latín Vulgar y Tardío en septiembre de 2014 en la Universidad de Oviedo nos llevó a hablar de la máscara de la onomatopeya que oculta tanto latín en el punto de partida de tantas y tantas palabras románicas. Era la ocasión para concluir, en atención a la sede ovetense, hablando del origen de bable 1 . Pero el apéndice de entonces ha tomado el cuerpo del presente artículo.

No carece de interés que ya Munthe daba fabula como segunda hipótesis etimológica: "Para la explicación de la palabra bable se ha propuesto, por una parte, balbus, balbulus; por otra,

1 Durante la celebración del congreso Clara E. Prieto Entrialgo, miembro del Comité de Organización, además de ser prudente objetora de la solución que proponíamos, nos proporcionó útiles informaciones bibliográficas $\mathrm{y}$, una vez concluido el trabajo, nos ha hecho interesantes sugerencias de detalle. Por todo lo cual, le expresamos aquí nuestro reconocimiento. Por otra parte, hemos realizado esta investigación, junto con la mencionada ponencia, en el marco del proyecto de "Semántica latino-románica" (ref. FFI2012-34826) que dirigimos. 
fabula. Pero en realidad la palabra aparece ya formada (acaso deformadamente de la antigua fabla $)^{\prime 2}$. A nuestro entender, esa sugerencia entre paréntesis da en la diana del origen de la palabra: bable no es otra cosa que una "deformación" de fabla. Pero analicemos antes la solución onomatopéyica que ha prevalecido.

Con no poca prudencia en lo que toca a la expresión inicial, se dice en el DCECH (1980, s. v. bable) que el nombre del dialecto asturiano "seguramente es onomatopeya para indicar el habla confusa y balbuciente de las personas de lenguaje imperfecto". En apoyo de esta hipótesis se compara la palabra con otras "formadas paralelamente", como el ingl. babble 'balbucear (niños o adultos)', al que pueden añadirse el dan. bable, el isl. babbla, el al. babbeln (pappeln) o el fr. babiller 'charlar, cascar'3. A su vez, García de Diego (1968, p. 152) pone la voz natural BABL, "onomatopeya del hablar confuso y balbuciente", como base de bable e insiste en que la -l- es elemento esencial de la onomatopeya, en contra de la opinión común que la considera un índice de valor frecuentativo. Menciona la supuesta relación con el cast. habla, "pero probablemente sería en su origen una denominación crítica de los que no entendieran bien el conjunto o algún dialecto suyo, de tan gran variedad en sus regiones".

No vamos a negar aquí la apariencia onomatopéyica de la palabra, tal como se desprende de las formaciones paralelas anteriores; pero sostenemos que su origen primordial reside en $\mathrm{FA}^{-}$ BLA, como apuntaba Munthe. Esa es una solución que prácticamente se descarta en el DCECH:

es sumamente improbable que el origen de bable tenga que ver con el de habla, pues el cambio de una F- latina en $b$ - solo se explicaría si el cambio hubiese pasado a través del vasco, donde no existe,

2 Munthe 1988 [1887], p. 5, n. 1.

3 EDEL 1978, s. v. babble; Lexis 1975, s. v. babiller: “ (d'une onomat. bab, indiquant le mouvement des lèvres : v. 1300)". 
o de haber habido cruce con el radical onomatopéyico babl-. Es preferible admitir que se trata de este únicamente.

Dado que la evolución fonética es improcedente, se abre la posibilidad al cruce de FABLA con el radical onomatopéyico babl-; pero inmediatamente se abandona por la opción de la onomatopeya plena, sin cruce alguno. Sin embargo, si el punto de partida está en FABLA, entonces el cruce posterior con la onomatopeya resulta muy probable.

En opinión de Gil (1990, p. 285), bable se remonta a la época de la romanización de Asturias. Hablando de topónimos bien conservados en la región (Lugones < Luggones, Argandenes < Arganticaeni, etc.), añade que sus habitantes "chapurreaban una lengua que sonaba extraña a oídos más romanizados: pues bable no ha de ser sino el adverbio barbare, con que los hispanos cultos y latinados motejaban el desaliño de aquellos pastores y guerreros barbare loquentes". En nota agrega que bable funciona como vascuence $<$ uasconice, a la vez que considera inciertos tanto el origen onomatopéyico como la derivación de habla. Ahora bien, la aplicación de BARBARE al empleo del sustrato romano no parece una hipótesis más segura.

El estado de la cuestión histórica y etimológica de bable lo ha resumido en dos páginas y media García Arias ${ }^{4}$ La palabra no se atestigua hasta el siglo XVIII y, como si careciera de tradición popular, se la conoce por medio de las citas de ciertos escritores. Lo cual no es una sorpresa, pues estas llegan como testimonios escritos, mientras aquella desde su origen pertenece a la tradición oral. Por ello, su documentación tardía no es prueba de que sea una voz de invención relativamente reciente. Designando el habla cotidiana en zonas rurales, nada de particular tiene que bable, con una larga trayectoria histórica, haya tardado en pasar del uso oral al texto escrito. ¡Cuántas otras palabras no han te- 
nido esa fortuna y sin atestiguación gráfica se han perdido en el largo y azaroso tránsito del latín al romance o ya en su etapa netamente románica!

La datación cronológica no debe separarse del aspecto geolingüístico. García Arias hace hincapié en el uso minoritario de bable con respecto a las expresiones habla asturiana o dialecto asturiano. El hecho de que a veces requiera una glosa en expresión disyuntiva ("lo que pertenece al bable o dialecto asturiano") es bastante indicativo de su mayor rareza. Ese empleo restringido de la palabra da pie a sospechar que bable ha debido de tener, dentro de la diversidad dialectal asturiana, un origen y evolución local. Lo que puede explicar sus dificultades de datación y sus limitaciones para generalizarse como denominación idiomática. Pero hay otros factores, entre los que destacamos el aspecto sociolingüístico que asocia bable al medio rural. Por designar en particular el habla rústica y menos fina, la palabra no se ha visto libre de connotaciones peyorativas. Por si fuera poco, las explicaciones etimológicas que han tenido mayor crédito, lejos de favorecer el buen uso de la palabra, han contribuido a perjudicarlo.

En efecto, García Arias acepta sin titubeos el adverbio ваRвARE como mejor étimo de bable:

Etimolóxicamente bable tien el so aniciu nel alverbiu llatín BARBARĒ 'en llingua estranxera', 'rudamente', 'al mou de los extranxeros', según construcciones posibles como barbare loqui 'falar basto, con faltes ${ }^{5}$.

Es verdad que, por su forma adverbial, BARBARE facilita una denominación en -e final, análoga a la de ROMANICE $>$ romance o vasconice > vascuence. Pero la facilidad de la forma no puede acallar el fuerte reparo de que en tal caso se trataría de un exónimo discriminatorio, como si hablar en bable hubiera sido 
en principio una modalidad 'bárbara, extraña'; esto es, un nombre dado desde fuera por los habitantes más romanizados, como decía Gil, a los que no pasaban de chapurrear el latín. Lo cual sería una sorprendente novedad en el mundo romano. Y si en el bable hubiera una mayor presencia de elementos de sustrato que en otros dialectos hispánicos, podría haber base para sostener tal hipótesis; pero ni siquiera una lengua tan diferente como el vascuence ha recibido un nombre semejante. Creemos, pues, que bable dista de ser un exónimo de esas características; muy al contrario, todo parece indicar que es nombre autóctono, autóctono latino, como el habla que designa.

Después de barbare, sin salir de la categoría adverbial, se piensa en el adverbio вALBE, como si el bable fuera un habla balbuciente: "tamién podría almitise la posibilidá de partir d'una metátesis del llat. BALBE, 'tatexando', 'escuramente', 'confusamente"'”6. En el plano expresivo вALBE resulta un étimo tan fácil que para llegar a bable solo ha de producirse el traslado de la -l-. Sin embargo, los inconvenientes de contenido no son inferiores a los de BARBARE. Mientras barbarus y barbare se aplican a la forma ininteligible de hablar y, consiguientemente, a los pueblos y a sus lenguas, balbus ('tartamudo') y balbe ('con tartamudeo') tienen referencia individual; es decir que los que balbucean son individuos y no los pueblos o sus lenguas. En este sentido nada apuntan los dos empleos de balbe (Lucrecio y Varrón), los únicos registrados en el ThLL, en los que se trata de apoyar la hipótesis, ni tampoco se halla ningún otro testimonio con semejante referencia bajo balbus o balbutire. Por tanto, las hipótesis que pretenden hacer descender bable de las formas adverbiales BALBE, indicando una forma de balbuceo, O BARBARE, como si se tratara de un modo de hablar extraño e ininteligible, nos parecen demasiado débiles. FABLA sugerida por Munthe y la base onomatopéyica, que merecen poco crédito a García Arias, son en nuestra opinión bastante más probables. En la primera situamos el origen de bable y la segunda 
pudo contribuir a la consolidación de la palabra e influir en su connotación peyorativa.

\section{Explicación morfológica y reinterpretación onomatopéyica}

Mientras $-a>-e($ sidre $=$ sidra $)$ es un resultado que se registra en algunas variedades del asturiano ${ }^{7}$, la $f$ - ha sido un gran obstáculo fonético para sostener FABULA > FABLA como étimo de bable. Nadie duda de la importancia capital que tiene la fonética histórica para comprender la evolución de las palabras. Ahora bien, en la conformación de estas influyen no pocas veces otros factores que tienen que ver con la estructura morfológica más que con las leyes fonéticas. Si cambiamos el punto de vista fonético por el morfológico, caeremos en la cuenta de que la mayor dificultad para identificar el étimo que proponemos aquí no reside exactamente en la $F_{\text {- }}$ de FABUlA, sino en la $b$ - inicial de bable. Es esta la que parece comunicarle valor onomatopéyico y le ha dado el aspecto de parónimo de barbare y balbe junto con el sentido peyorativo. Es inútil recargar las tintas sobre ese sentido negativo de fabla, tan pronto como se acerca a bable, pues en principio no le es propio. Antes bien, solo fabula, como étimo auténtico, puede acallar los malos ecos que parece suscitar bable.

Desde el punto de vista histórico, como variedad lingüística, el bable es la continuación regional del latín vulgar. Puesto que entendemos la expresión latín vulgar sin connotación despectiva, al menos desde que se constituye en denominación técnica de la lengua común no literaria ${ }^{8}$, creemos que bable tampoco merece semejante señalamiento $\mathrm{y}$, en consecuencia, debe ser cohonestado como nombre del habla popular de la llingua asturiana. Recordemos que el latín antes de ser la lengua de Roma, antes de hacerse urbano, es la lengua del Lacio, la lengua de una sociedad rural, y que la mayor parte del léxico latino fundamental no ha

7 Andrés Díaz 2013, p. 81.

8 García-Hernández 2015. 
logrado desprenderse del natural olor a campo. En el origen de cualquier familia léxica hay parientes humildes y, cuando decimos humildes, solo queremos decir apegados a la tierra, como indica el adjetivo humilis, cuya base humus ('tierra') no deja de ser la de homo y humanus.

Que el origen de bable está en el lat. FABULA > FABLA se le puede ocurrir a cualquiera, pues en definitiva el bable no es sino fala. Pero, mientras el sustantivo fala es evolución fonética normal de fabla en asturiano y en iberorromance occidental, bable es una variante morfológica que se remonta también a fabla y se diferencia menos de este que de fala. Si esto es así, el que bable no se atestigüe con anterioridad al s. XVIII no es óbice para que la palabra haya tenido una tradición multisecular. Pero si el paso de fabla a bable no resiste la explicación fonética, este es el momento de mostrar otra vía de solución al drástico cambio morfológico que ha conferido a la palabra un aspecto onomatopéyico. Ello supondrá retirarle la máscara que oculta su verdadero origen y ha hecho entenderlo como si fuera la imitación de un blablá bárbaro o balbuciente.

En efecto, la $b$ - inicial de bable tiene toda la pinta de no ser original y haber enmascarado la procedencia de la palabra. Esa primera $b$ - que no resulta de una evolución fonética regular es ante todo producto de la duplicación de la segunda - $b-$ - Se trata de un cambio morfológico en la estructura de la palabra que se configura sobre la reduplicación silábica de la misma consonante. La $b$ - inicial de bable es adventicia como la $t$ - del fr. tante ('tía'), procedente del lat. Aмiтa ('tía paterna'), $t$ - que no tenía el francés medieval ante ni tiene el ingl. aunt. Es el mismo fenómeno reduplicativo del mall. konko y del camp. kunku, procedentes de AuUnCulus ('tío materno'), como el fr. oncle 9 .

La reduplicación consonántica, común en los términos de parentesco y característica de la lengua afectiva infantil, familiar y

9 REW 1972, § 838. 
popular, consiste, pues, en repetir la misma consonante en sílabas consecutivas, bien donde no hay ninguna, como en $t$-ante $\mathrm{y}$ $k$-onko, bien donde hay otra que se asimila a la predominante; así el lat. bibo ('beber'), procedente del protoitálico *pibelo- (cf. sic. $\pi(\beta \varepsilon)^{10}$. En este caso, sacrificar una consonante lleva consigo reforzar la otra y ese refuerzo es característico del lenguaje elemental, como es el habla infantil que forma palabras de estructura sencilla. Un niño que pide el chupete, si prescinde de la primera sílaba, sobre la forma (chu-)pete puede crear pepe o tete; o si pide el móvil puede transformar, ocasionalmente, m-óvil en bóvil. La transformación de la $b$ - inicial de bable es como la ch- de chocho en principio 'grano (rojo)', doblete de cocho (con referentes tan diversos como 'cerdo' o 'perro'), que procede del lat. cocceus 'de color rojo', adjetivo de coccum 'agalla de la cochinilla', o como la ch- de las variantes chucho ('perro') y chocha (ave con plumaje de color gris 'rojizo' $)^{11}$. Si reparamos en el ingl. Bob, hipocorístico de Robert, comprobamos que en él se ha producido el mismo cambio en $b$-inicial que en bable, naturalmente por influencia de la $-b$ - siguiente, tras la que se pierde el resto de la palabra: $R$-ob(ert) $>B-o b$. Eso no quiere decir que bable haya sido una formación infantil, sino más bien familiar y afectiva.

No parece que los etimólogos modernos, siempre atentos a los cambios fonéticos, hayan concedido a la reduplicación silábica la importancia que merece como factor de la morfología léxica. Ese déficit de atención contrasta con el exceso atribuido a la onomatopeya. A menudo basta ver la repetición de una consonante para suponer que se trata de una palabra imitativa. Si no fuera conocido el étimo de la palabra gragea, no sería extraño encontrar una explicación más o menos así: voz creada a partir de la onomatopeya grag-, ruido que se hace al paladear o masticar una gragea. Esto es, un étimo análogo al que se da de cocho o guarro, como si provinieran de las voces de llamada coch y guarr.

10 André 1978, p. 96; EDLIL 2008, s. v. bibo.

11 García-Hernández 2013a, pp. 51-56. 
Por fortuna, la entrada de aquella en español tiene datación y se conoce su procedencia. La $g$ - inicial es espuria, de manera que gragea ha reemplazado la forma antigua dragea, préstamo del fr. dragée, a su vez, procedente del lat. tragemata (especie de 'postre'). Quizá ese cambio de la consonante inicial no ha sucedido sin el cruce de grano.

Los cruces morfológicos se prestan a remotivar el origen. Por ello, no quisiéramos caer en el extremo contrario sin admitir que formas onomatopéyicas, cual la base BABL, hayan podido influir en la consolidación y reinterpretación del vocablo bable, una vez modificado por reduplicación silábica. La cercanía referencial, significativa o evocativa de dos palabras las empuja a cruzar sus formas, sobre todo si estas son también próximas y aún sin serlo. Para no ir más lejos, el cast. hablar, que contiene el mismo radical propuesto aquí para bable, se cruzó con su sinónimo parlar, préstamo de la Romania central que heredó el lat. parabolare, en la locución jocosa ni hablar ni pablar, usada para indicar silencio absoluto $^{12}$.

Es un hecho que la reduplicación silábica ha oscurecido el parentesco de bable con FABULA > FABLA, hasta hacerlo caer en la compañía de BARBARE у BALBE, como si fuera una triste imitación del blablá. Sin embargo, el bable no consiste en barbare o balbe fabulari; no es una barbara o balba fabula; tan solo es la fabla natural del país. Eso quiere decir que bable tiene un carácter fundamentalmente sustantivo, lejos de las modalidades adverbiales barbare y balbe. Si con ellas se ha tratado de buscar un origen adverbial paralelo al de romance (< lat. romanice) y vascuence (< lat. uasconice), estas son netamente objetivas, mientras las adjudicadas

12 En la primera edición (Valencia 1511) del Cancionero General de Hernando del Castillo se ha supuesto la existencia de una forma babla que, con el significado de 'habla confusa o necia' o simplemente 'habla', podría ser un antecedente de bable (DCECH (1980, s. v.; ya en el DCELC 1954, s. v.; también García de Diego 1968, p. 152). Sin embargo, Joaquín González Cuenca, último editor del Cancionero (Hernando del Castillo 2004, II, p. 250), nos comunica que en la edición de 1511 se lee claramente 'habla'. 
a bable son negativas y descalificatorias; la referencia de barbare es menos gentilicia que articulatoria, al igual que la de balbe. Esa remisión etimológica a adverbios extraños ha contribuido y contribuye no poco, según hemos dicho, a impregnar de sentido despectivo la palabra. Por tanto, en principio bable no es creación onomatopéyica. Si la palabra se siente y se reinterpreta como onomatopeya, esta no es original, sino sobrevenida, como efecto secundario de la reduplicación silábica que nivela la consonante labial de la primera sílaba con la de la segunda.

Superada, pues, la dificultad mayor que representa la $b$ - inicial, otras menores carecen ya de importancia. Por tratarse de un cambio morfológico, es posible que bable, con su aspecto novedoso, haya tenido un punto de partida muy local, a la vez que se generalizaba fala como resultado regular de la evolución fonética. El cierre de la - a final de fabla en bable habrá favorecido el cambio al género masculino, como ocurre en el asturleonés Las Arribes, corónimo salmantino de la margen izquierda del Duero, próximo a Portugal, que pasa a ser Los Arribes entre los castellanohablantes. En cambio, los propios usuarios del bable mantendrían normalmente *la bable, como la sidre ${ }^{13}$.

En el proceso de evaluación de este trabajo un informante anónimo nos ha brindado la plausible sugerencia de que la -e permita ver en bable un derivado posverbal de fablar, análogo a cante y pringue respecto de cantar y pringar. Desde aquí le expresamos nuestro reconocimiento. Pudo ser así o quizá no es necesario llegar al derivado posverbal, si *fable surgió directamente como variante de fabla, según el procedimiento explicado en el párrafo anterior; sin apoyo verbal, el fenómeno se da asimismo en castellano (alfalfa y alfalfe). En cualquier caso, el cambio de la vocal final $\left({ }^{*} f a b l-e\right)$ no solo sería anterior al de la consonante ini-

13 No obstante, también en este caso se documenta el sidre, fenómeno que, según nos explica Clara E. Prieto, puede "estar favorecido por el carácter semántico continuo de sidra, que lo hace combinarse con adjetivos neutros: la sidra fresco / la sidre fresco / el sidre fresco". 
cial (b-able), sino que de él surgiría la bifurcación del doblete fabla I *fable, con resultado dispar en fala / bable.

Es más, la nueva forma hipotética *fable no deja de presentar cierto interés sociolingüístico y sobre todo cronológico. Pudo haber aparecido, precisamente, para diferenciar una modalidad de habla inferior a la que se entendía normalmente como fabla. Y a diferencia de esta, que fue ya sin duda forma sincopada latina mucho antes que protorrománica, "fable sería plenamente románica; pero, como variante de fabla, anterior a la forma evolucionada fala. Habida cuenta, pues, de este término ante quem de *fable, cabe suponer también que bable sea bastante más remoto de lo que sugieren sus testimonios dieciochescos.

Sea como fuere, la larga evolución desde faBla a bable, pasando por la forma intermedia ${ }^{*}$ FABLE, es un buen ejemplo de la fluida Corriente de la lengua hablada, en su milenario curso latinovulgar y románico, hasta adquirir formas imitativas de apariencia onomatopéyica. En este y en otros muchos casos es inútil apelar al origen onomatopéyico, pues se trata de palabras que no han surgido por imitación de sonidos naturales. El esp. cocho y cochino y el fr. coche y cochon no se han formado a partir de una voz previa coch coch, repetida para llamar la atención del cerdo, o de cualquiera de sus variantes regionales, según se lee en Rohlfs (1968, pp. 205-206) y en cualquier diccionario etimológico, sino que son estas voces las que se han creado sobre unos nombres aplicados en principio al cerdo como adjetivos de color (porcus cocceus, coccinus) ${ }^{14}$. Asimismo, la palabra bable, aunque haya adquirido la apariencia de voz onomatopéyica, sobre todo gracias a la reduplicación consonánti$\mathrm{ca}$, no deja de tener el valor original de 'habla' o 'forma peculiar de hablar', como descendiente del lat. FABULA > FABLA.

Por tanto, bable no deja de ser una denominación propia del habla popular, local y regional de Asturias. Como nombre castizo de la lengua asturiana hablada, bable no es sino una variante 
morfológica de fala y no es diferente del habla castellana, de la fala gallega o de cualquier otra fala de las que aún sobreviven al oeste de la Vía de la Plata. Más allá de la cuestión del nombre, como manifestación oral de la lengua asturiana, como habla propia del país, el bable es continuación genuina del latín vulgar. He ahí, pues, un origen remoto, un origen que seguramente se remonta al amanecer de la romanización de Asturias, cuando hablar en latín era ya fabulare y el habla era fabula > fabla. Y desde FABLA, voz latina y románica, se llega lo mismo a bable por evolución morfológica que a fala por evolución fonética. Por muy local que haya sido el origen de bable, estaremos de acuerdo en que su uso no es menos legítimo que el de fala o habla.

Durante siglos de analfabetismo popular el bable, con su diversidad dialectal propia, ha sido el habla que ha sostenido lo que hoy es la "llingua" asturiana o el asturiano. Como rama o vástago del tronco latino, por más humilde que sea, difícilmente podría ser considerada bárbara. Si el bable nació tras la romanización del territorio astur, no puede considerarse ni por sus hablantes ni por sí misma una lengua bárbara. ¿Es una lengua ruda? En cuanto que ha pasado siglos como dialecto sin cultivo literario, lo será en mayor o menor medida. Pero, como lengua hablada el bable no puede menos de ser familiar y a la vez, por el origen (fabla) de su nombre, afable. Desde la perspectiva de la lengua latina y muy en particular desde el latín vulgar, cuyo nombre, tildado también a menudo de tonalidad peyorativa, ha logrado consagrarse como denominación técnica, no podemos menos de sentir viva simpatía por la pervivencia natural del bable, una de sus hijas menores.

\section{Bibliografía}

André, JacQues. Les mots à redoublement en latin, París, Klincksieck, 1978.

Andrés DíAz, Ramón De. Gramática comparada de las lenguas ibéricas, Gijón, Ediciones Trea, 2013. 
Dcech: Joan Corominas \& José A. Pascual. Diccionario crítico etimológico castellano hispánico, Madrid, Gredos, 1980.

DCelc: Joan Corominas. Diccionario crítico etimológico de la lengua castellana, Madrid, Gredos, 1954.

DraE: Real Academia Española. Diccionario de la lengua española, Barcelona, Espasa Libros, 2014.

Edel: Walter W. Skeat. An Etymological Dictionary of the English Language, Óxford, Clarendon, 1978.

EdLIL: Michiel de Vaan. Etymological Dictionary of Latin and the other Italic Languages, Leiden, Brill, 2008.

García Arias, Xosé Lluis. Propuestes etimolóxiques (4) del Diccionariu etimolóxicu de la Llingua Asturiana, Uviedo, Academia de la Llingua Asturiana, 2009.

García de Diego, Vicente. Diccionario de voces naturales, Madrid, Aguilar, 1968.

García-Hernández, Benjamín. «Del lat. coccum, cocceus y coccinus al esp. coco, cocho, cochino y cochinilla», Revista de Filología Española 93, 2013a, pp. 41-70.

García-Hernández, B. "El origen ignoto de coche y cochon", Polyphonia Romana. Hommages à Frédérique Biville, A. Garcea \& al., eds., Hildesheim, Olms, 2013b, 169-182.

García-Hernández, B. «Nombre y concepto de latín vulgar. Vulgus, uulgo y uulgaris. Generalidad y diversidad», Latin vulgaire - latin tardif 11, Alfonso García Leal, ed., Oviedo, Universidad de Oviedo, 2015, (en prensa).

Gil, Juan. «Notas de toponimia», Studia indogermanica et palaeohispanica in honorem A. Tovar et L. Michelena, F. Villar, ed., Salamanca, Ediciones Universidad de Salamanca, Servicio editorial de la Universidad del País Vasco, 1990, pp. 285-290.

Hernando del Castillo. Cancionero general, Joaquín González Cuenca, ed., Madrid, Castalia, 2004. 
LExIs. Dictionnaire de la langue française, Jean Dubois, dir., París, Larousse, 1975.

Munthe, Åke W:son. Anotaciones sobre el habla popular de una zona del occidente de Asturias, trad. de M. ${ }^{a}$ Berta Pallarés, ed. de Ana M. a Cano González, Uviéu, Universidad de Oviedo, 1988 [1887].

Rew: Wlihelm Meyer-Lübke, Romanisches etymologisches Wörterbuch, Heidelberg, C. Winter, 1972.

RoHLFs, GERHARD. «Traditionalismus und Irrationalismus in der Etymologie», Festschrift Walther von Wartburg zum 80. Geburtstag, K. Baldinger, ed., Tubinga, Niemeyer, 1968, II, pp. 197-212,

THLL: Thesaurus lingua latinae, Leibzig, Teubner, 1900 ss.

Benjamín García-Hernández Universidad Autónoma de Madrid 
